\title{
Patroon en argument
}

\section{Een dubbelfeestbundel bij het emeritaat van William Van Belle en Joop van der Horst}

Onder redactie van Freek Van de Velde, Hans Smessaert, Frank Van Eynde, Sara Verbrugge

Met bijdragen van Liesbeth Augustinus (KU Leuven), Hans Broekhuis (Meertens Instituut), Filip Buekens (KU Leuven), Paul Claes (KU Leuven), Marja Clement (University of Zürich), Timothy Colleman (U Gent), Bert Cornillie (KU Leuven), Evie Coussé (University of Gothenburg), Kristin Davidse (KU Leuven), Georges De Schutter (UA), Hendrik De Smet (KU Leuven), Lorenz Demey (KU Leuven), Gunther De Vogelaer (University of Münster), Sarah D'Hertefelt (KU Leuven), Sylvain Dieltjens (KU Leuven), Kristien Dieussaert (KU Leuven), Luk Draye (KU Leuven), Flip Droste (KU Leuven), Els Elffers (UvA), Kurt Feyaerts (KU Leuven), Dirk Geeraerts (KU Leuven), Marinel Gerritsen (Radboud U Nijmegen), Paul Gillaerts (KU Leuven), Elvira Glaser (University of Zürich), Pierre Godin (UCL), Ingeborg Harmes (University of Münster), Priscilla Heyndrickx (KU Leuven), Jack Hoeksema (RU Groningen), Wim Honselaar (UvA), Matthias Hüning (FU Berlin), Leen Janssen (KU Leuven), Theo Janssen (VU Amsterdam), Karolien Janssens (UA), Koen Jaspaerts (KU Leuven), Evelien Keizer (University of Vienna), Wim Klooster (UvA), Karen Lahousse (KU Leuven), Béatrice Lamiroy (KU Leuven), Odo Leys (KU Leuven), Ester Magis (VUB), Ann Marynissen (University of Cologne), Patrick Meuris (KU Leuven), Jan Noordegraaf (VU Amsterdam), Jan Nuyts (UA), Bert Oben (KU Leuven), Albert Oosterhof (KU Leuven), Jan Pekelder (Sorbonne, Paris, Charles University in Prague), Harry Perridon (UvA), Jill Puttaert (VUB), Arend Quak (UvA), Tom Ruette (HU Berlin), Gijsbert Rutten (Leiden University), Walter Schaeken (KU Leuven), Ina Schermer-Vermeer (UvA), Ineke Schuurman (KU Leuven), Hans Smessaert (KU Leuven), Jan Stroop (UvA), Dorien Van de Mieroop (KU Leuven), Freek Van de Velde (KU Leuven), Hans Van de Velde (Utrecht University), Johan van der Auwera (UA), Sander van der Harst (Utrecht University), Marijke van der Wal (Leiden University), Jacques Van Keymeulen (U Gent), Daniël Van Olmen (UA, University of Lancaster), Marc van Oostendorp (Leiden University), Vincent Vandeghinste (KU Leuven), Roxane Vandenberghe (U Gent), Aleydis Vandenbossche (VUB), Wim Vandenbussche (VUB), Ton vanderwouden (Meertens Instituut), Willy Vandeweghe (U Gent, KANTL), Frank Van Eynde (KU Leuven), Sara Verbrugge (KU Leuven), JeanChristophe Verstraete (KU Leuven), Ulrike VogI (University of Vienna), Rik Vosters (VUB), Fred Weerman (UvA), Roland Willemyns (VUB), Eline Zenner (KU Leuven

(C) 2014 by Leuven University Press / Presses Universitaires de Louvain / Universitaire Pers Leuven, Minderbroedersstraat 4, B-3000 Leuven (Belgium)

ISBN 9789462700147

D / 2014 / 1869 / 59

Distributed by Leuven University Press

http://upers.kuleuven.be/nl/book/9789462700147

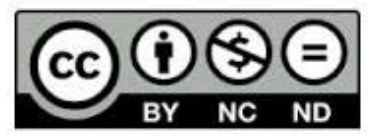

This work is licensed under a Creative Commons Attribution-NonCommercial-NoDerivs 3.0 Unported License: http://creativecommons.org/licenses/by-nc-nd/3.0/ 
FREEK VAN DE VELDE, HANS SMESSAERT

FRANK VAN EYNDE, SARA VERBRUGGE (RED.)
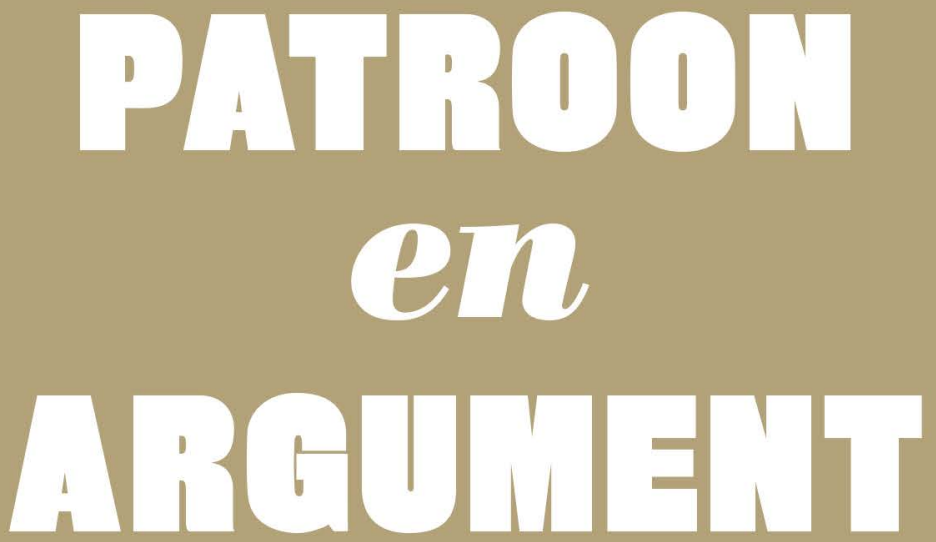

\section{Een dubbelfeestbundel}

bij het emeritaat van

WILLIAM VAN BELLE

EN

JOOP VAN DER HORST 


\section{PATROON EN ARGUMENT}




\section{Patroon en argument}

Een dubbelfeestbundel bij het emeritaat van William Van Belle en Joop van der Horst

Onder redactie van

Freek Van de Velde

Hans Smessaert

Frank Van Eynde

Sara Verbrugge 
(c) 2014 Universitaire Pers Leuven / Leuven University Press / Presses Universitaires de Louvain. Minderbroedersstraat 4, B-3000 Leuven

Alle rechten voorbehouden. Behoudens de uitdrukkelijk bij wet bepaalde uitzonderingen mag niets uit deze uitgave worden verveelvoudigd, opgeslagen in een geautomatiseerd gegevensbestand of openbaar gemaakt, op welke wijze ook, zonder de uitdrukkelijke voorafgaande schriftelijke toestemming van de uitgevers.

ISBN 9789462700147

D/ 2014 / 1869 / 58

NUR: 623

Ontwerp cover: Griet Van Haute

Opmaak: Friedemann BVBA 


\section{Inleiding}

"twee hoogleeraren, sieraden hunner universiteit, die hun tijd niet te kostbaar achtten om in breedvoerige betoogen hun vooropgezette meening kracht van bewijs te geven"

(uit: Jacobs, A.H. 1899. Vrouwenbelangen. Drie vraagstukken van actueelen aard. Amsterdam: L.J. Veen)

P 1 oktober 2014 zwaaiden twee hoogleraren Nederlandse taalkunde af aan de Leuvense universiteit: William Van Belle en Joop van der Horst. Jarenlang hebben ze hun stempel gedrukt op de opleiding. Een gunstig stempel, zeker als je de mening vraagt van de afgestudeerden, want beiden waren populaire docenten. En dat bereikten ze niet door het niveau van hun vakken te laten zakken in een slecht ingelicht idee van hoe je de studenten ter wille kunt zijn. Integendeel, het basisvak syntaxis van William Van Belle was voor tal van studenten een onneembare horde, en gold als een efficiënte manier om de onvermijdelijke schifting van de eerstejaarsstudenten door te voeren, en Joop van der Horst stond bekend om zijn Hollandse zuinigheid als het op cijfers geven aankwam. Meer dan één gevorderd student uit de bovenbouw die ervan uitging dat de buit al binnen was en er zich gemakkelijk van afmaakte bij het studeren, keek ontzet naar zijn resultatenblad, waar een kletterende onvoldoende voor Middelnederlands op stond. Wat hen dan wel zo populair maakte, was hun beider volslagen gebrek aan capsones. Thesisstudenten werden hartelijk ontvangen, verstandige vragen tijdens of na het college werden uitvoerig behandeld, minder verstandige vragen werden tactvol afgehandeld en uitnodigingen voor deelname aan extracurriculaire activiteiten werden meestal aangenomen. Die pretentieloze, joviale aanpak kenmerkte trouwens ook hun omgang met de collega's. In een departement waar soms stennis gemakkt wordt over bagatellen de universiteit is hierin niet anders dan enige andere werkplek - was William, als departementsvoorzitter gedurende vele jaren, de juiste man op de juiste plaats om de sociale brandjes te blussen voor ze uitsloegen. Het is ook niet verwonderlijk dat beide heren het uitstekend met elkaar 
konden vinden. Ze zijn vrienden geworden, en daar heeft hun emeritaat naar verluidt niets aan veranderd. Net zoals bij de studenten was hun joviale reputatie niet gebaseerd op opportunisme. Menig collega heeft aan William en Joop een hardnekkige wetenschappelijke tegenstander gehad: ze waren bepaald niet uit het lood te slaan in verwoede discussies op doctoraatsverdedigingen, lezingen en op papier, en konden tot wanhoop én ontzag van hun collega's uit het niets doorslaande argumenten tevoorschijn toveren die een zorgvuldig opgebouwd en onwankelbaar geacht standpunt van tafel vermochten te vegen. Met de titel van dit boek, Patroon en argument, en met het motto dat boven deze inleiding prijkt, hebben we hulde willen brengen aan het karakter en de beroepsernst van deze twee bijzondere neerlandici, en met name aan hun vermogen om patronen bloot te leggen in het taalgebruik, in zijn historische, sociale en pragmatische dimensies, en hun betoog overtuigend te maken door het te ondersteunen met een verbijsterend scala aan doortimmerde argumenten. Dat het woord patroon een extra betekenis heeft, die enigszins vloekt met het ni dieu ni maître gehalte van de jubilarissen, moet de lezer maar voor lief nemen.

Deze twee hoogleraren, wars van opportunistische vleierij of gekonkel, zullen erg gemist worden aan het departement. We dachten dan ook dat het passend was om dit dubbelemeritaat te markeren met iets tastbaars. We zaten met de handen in het haar, want je kunt niet met eender wat komen aanzetten. In zijn boek Taal op drift (2013, dus kort vóór zijn eigen emeritaat) laat Joop zich laatdunkend uit over de studenten van de Deense taalkundige Otto Jespersen (1860 - 1943), die de legendarische hoogleraar bij zijn afscheid bedachten met een bloemenvaas, wat de auteur toch een beetje minnetjes vond. Géén bloemenvaas dus. Een huldealbum dan? Dat lag niet voor de hand. Huldealbums zijn niet populair, vooral bij contribuanten. Daar zijn verschillende redenen voor. Allereerst dat ze bibliometrisch minder doorwegen dan tijdschriftartikelen, wat ze in het huidig tijdsgewricht een verlieslatende post maakt. Verder is het afgelopen decennium een grootscheepse generatiewissel aan de gang, waardoor academici in de leeftijdsklasse tussen zeg 55 en 75 jaar, een voltijdse baan hebben aan het vullen van huldealbums voor hun emeriterende collegae. Als je een oproep doet om een bijdrage te leveren voor een huldealbum, loop je het risico dat je te weinig reacties krijgt, of alleen van mensen die verder niet veel om handen hebben, zodat de auteurslijst een flauwe afspiegeling is van de eigenlijke waardering 
onder collega's. In ons geval liepen we het bijkomende risico dat er zich een scheve verdeling van hulde-artikelen voor elk van beide emeriti zou kunnen voordoen: een stroom artikelen voor William en een paar halve kladjes voor Joop, of vice versa. Die bezwaren hebben we onverschrokken genegeerd, en we zijn gaan peilen naar interesse, en kijk: dat bleek buitengewoon mee te vallen. Bijna iedereen die we aanschreven was enthousiast, al zijn sommige collega's er uiteindelijk niet toe gekomen ook werkelijk een stuk in te leveren, vaak om begrijpelijke redenen. Niettemin bleken er ook na deze onvermijdelijke selectie nog ruim voldoende stukken voorhanden om een bundel mee te vullen. Eigenlijk was dat een nieuw probleem: het was al vroeg duidelijk dat we de kaap van de 500 bladzijden makkelijk zouden ronden, waardoor de kostprijs voor het uitgeven schrikbarend steeg. Daar kwam van uitgeverswege nog de begrijpelijke bezorgdheid bij dat het boek daardoor nog meer onverkoopbaar zou worden dan een in het Nederlands geschreven verzamelband over taalkunde toch al is: een aanzienlijk deel van de potentiële afzetmarkt is als auteur betrokken bij het boek, en gaat zich niet bovenop het presentexemplaar nog een tweede exemplaar aanschaffen. En als de situatie aan onze faculteit representatief is, en ook elders de vakbibliotheken kampen met krimpende budgetten voor de aanschaf van boeken, onder andere door de hoog oplopende kosten voor tijdschriftabonnementen, dan moeten ook van die kant geen royale bestelorders verwacht worden. We willen de Universitaire Pers Leuven dan ook van harte bedanken de uitgave van dit boek te hebben willen ondersteunen. Daarvoor moeten we eigenlijk ook Joop van der Horst zelf dankbaar zijn, want die heeft veel eigen werk in het fonds van de UPL, zodat die zich toch ook een beetje moreel onder druk gezet gevoeld moet hebben. Niettemin kon de uitgave natuurlijk alleen tot stand komen met bijkomende financiering. Daarvoor willen we van harte de volgende subsidieverstrekkers bedanken: de opleiding Taal \& Bedrijf, de onderzoeksgroep ComForT, het Centrum voor Computerlinguïstiek (CCL), de groep Reasoning, Argumentation \& Thinking, de faculteit Letteren en het tijdschrift Leuvense Bijdragen. Een bijzondere vermelding verdient Willy Smedts, die het grootste deel van het budget voor zijn rekening nam, Dorien Van de Mieroop, die de budgetten van Taal \& Bedrijf vrijgaf en Walter Schaeken, die geld kon vrijmaken van de groep Reasoning, Argumentation \& Thinking. Het lijkt ons redelijk dat de gefêteerden deze gulheid te gelegener tijd testamentair vereffenen. Verder willen we ook de reviewers bedanken die de stukken mee nagelezen 
hebben en de auteurs hebben behoed voor overgeslagen stappen in de redenering, over het hoofd gekeken vakpublicaties of onzorgvuldige formuleringen. Het is een lange lijst: Liesbeth Augustinus, Johan van der Auwera, Ronny Boogaart, Julie Van Bogaert, Kenneth Boumann, Geert Brône, Filip Buekens, Ingrid Van Caneghem-Ardijns, Peter-Arno Coppen, Evie Coussé, Jeroen Van Craenenbroeck, Kristin Davidse, Johan De Caluwé, Steven Delarue, Lorenz Demey, Karen Deschamps, Filip Devos, Sigurd D'hondt, Sylvain Dieltjens, Lobke Ghesquière, Paul Gillaerts, Jan Goossens, Jan Heylen, Priscilla Heynderickx, Jack Hoeksema, Koen Jaspaert, Dany Jaspers, Jacques Van Keymeulen, Karen Lahousse, Alexandra Lenz, Sterre Leufkens, Piet Mertens, Dorien Van De Mieroop, Frank van Meurs, Jan Nuyts, Marc van Oostendorp, Albert Oosterhof, Tom Ruette, Gijsbert Rutten, Ineke Schuurman, Jan Stroop, Michiel de Vaan, Reinhild Vandekerkhove, Willy Vandeweghe, Jean-Christophe Verstraete, Ton van der Wouden en Eline Zenner.

We hopen dat de bijdragen in dit boek de inspiratie zullen vormen voor nieuw werk, want we kunnen ons niet voorstellen dat Joop en William hun emeritaat in ledigheid zullen doorbrengen.

Freek Van de Velde

Hans Smessaert Frank Van Eynde Sara Verbrugge 


\section{INHOUD}

\section{Deel I}

\section{Syntaxis en morfologie}

Willy Vandeweghe

De ANS en het plaatsschema van de hulpwerkwoorden

\section{Pierre Godin}

Over IPP, 'lange en korte infinitieven' en aanverwante constructies: werkwoorden over de grenzen heen van de morfologie, de syntaxis en de semantiek

Frank Van Eynde, Liesbeth Augustinus, Ineke Schuurman \& Vincent Vandeghinste

Het verrassende resultaat van een copulativiteitspeiling

Harry Perridon

Enige opmerkingen over de vorm van persoonlijke voornaamwoorden in koppelzinnen

Hendrik De Smet

De integratie van Engelse leenwerkwoorden in het Nederlands

Georges De Schutter

Een overzicht van PP-objecten en PP-complementen

Hans Broekhuis

Dubbel-voorzetselobjectconstructies?

Timothy Colleman

Nog eens de dubbel-voorzetselobjectconstructie

Odo Leys

Nog eens de trajectconstructies van het type de trap op 


\section{Wim Honselaar \& Evelien Keizer}

De semantische categorie Tijd in Functional Discourse Grammar: syntaxis en semantiek van voorzetselloze temporele uitdrukkingen in het Nederlands

Karen Lahousse \& Béatrice Lamiroy

Grammaticalisatie en taalvergelijking: Nederlands het is zo dat vs Frans c'est ainsi que

Ton van der Wouden

Is hier sprake van een nieuwe existentiële constructie?

Marja Clement \& Elvira Glaser

Hoe krijg je dit gepubliceerd?

'Krijgen'-constructies in het Nederlands

Daniël Van Olmen \& Johan van der Auwera

Over $z$ ón en zo meer

Ina Schermer

Manneken Pis en wandelaar Bastet.

Over lidwoordloze eigennaamsgroepen en de (ontbrekende)

correspondentie met een naamwoordelijk gezegde

Luk Draye

Man en men: een wereld van verschil

Wim G. Klooster

Re er

Jan Pekelder

Het Nederlandse subject een taalteken?

Over SUB-PV-DOB- en PV-SUB-DOB-strings

Fred Weerman

De januskop van complexiteit 


\section{Deel II}

\section{Historische taalkunde en historiografie}

\section{Marc van Oostendorp}

De geboorte van de jambe uit de geest van het Nederlands

Sander van der Harst \& Hans Van de Velde

Wordt leggen schijnbaar of werkelijk liggen?

Bert Cornillie

Over de subjectieve lezing van dreigen in het $16^{\mathrm{de}}$ - en

$17^{\text {de }}$-eeuwse Nederlands.

Historische pragmatiek vs contact-geïnduceerde taalverandering 329

Evie Coussé \& Freek Van de Velde

Hulpwerkwoordselectie in drieledige perfecta met een modaal.

Een alternatieve historische verklaring

Ingeborg Harmes

Wat zou het?

Een synchrone en diachrone analyse van zou(den)

Karolien Janssens \& Jan Nuyts

Me dunkt!

Een diachrone blik op dunken

Marijke van der Wal \& Gijsbert Rutten

Negatieverschijnselen revisited

Gunther De Vogelaer \& Roxane Vandenberghe

Omwille van Joop

Een onderzoek naar de geschiedenis van een

voorzetseluitdrukking

Jack Hoeksema

De opkomst van aan als verbindend element in

maatnomenconstructies 


\section{Matthias Hüning}

Over complexe preposities en convergentie

Jan Stroop

't Ene dan is 't andere niet

Aad Quak

De Oudnederlandse appellatieven op -ing

Albert Oosterhof \& Paul Gillaerts

Zijn pachtbrieven formulieren?

Het formulaire karakter van pachtcontracten uit het Leuvense schepenarchief

Ann Marynissen \& Theo A.J.M. Janssen

Vroegnieuwnederlands voor commercie en cultuur

Dirk Geeraerts

Zellig Harris en het contemporaine corpuslinguïstische distributionalisme

Jan Noordegraaf

Verre verwanten.

D.C. Hesseling (1859-1941) over taal en taalverandering

Pragmatiek, toegepaste taalkunde \& taalpolitiek

Filip Buekens

'Buiten de taal treden' - wat zou dat kunnen betekenen?

Lorenz Demey \& Hans Smessaert

Logische geometrie en pragmatiek 
Leen Janssens, Sara Verbrugge, Kristien Dieussaert \& Walter Schaeken

Maar hoe zit dat eigenlijk?

Paul Claes

Claus als retoricus

Kristin Davidse

Constructionele semantiek en pragmatiek in de analyse van gekloofde zinnen

Els Elffers

Uitroepende zinnen

Patrick Meuris

Structuursignalen in verklarende teksten

Jean-Christophe Verstraete \& Sarah D'Hertefelt

Polariteitsomkering bij insubordinatie

Sylvain Dieltjens \& Priscilla Heynderickx

Vertrouwen in de oncoloog?

Analyse van consultaties in een palliatief zorgtraject

Kurt Feyaerts \& Bert Oben

Prettig leedvermaak.

Onderzoek naar gelaagde betekenissen in het CORINTH-corpus 667

Dorien Van De Mieroop

Een verkenning van de pragmatische functies van directe rede in narratieven

Flip Droste

Het Nederlands Bedreigd? Bullshit!

Marinel Gerritsen

Vlamingen en Nederlanders: van cross- naar intercultureel onderzoek 


\section{Koen Jaspaert}

En is ' $t$ de tale niet, wat is ' $t$ dan dat mij kwelt

Ester Magis, Jill Puttaert, Aleydis Van den Bossche, Wim Vandenbussche, Rik Vosters \& Roland Willemyns

Tussen adoptiekoe en zemelteef: iets over de houdbaarheidsdatum van 'verse woorden' in Vlaamse en Nederlandse kranten

Jacques Van Keymeulen

De afkortingencultus

Ulrike Vogl

"Als u meer talen kent, lijdt uw moedertaal": studenten

Nederlands en hun visie op taal

Eline Zenner, Tom Ruette \& Freek Van de Velde

Taalkeuze in personeelsadvertenties: een verkennend onderzoek door drie science floor managers 


\title{
Negatieverschijnselen revisited
}

\author{
Marijke van der Wal \& Gijsbert Rutten
}

(Universiteit Leiden)

$I^{\prime}$

$n$ een klassiek artikel uit 1979 bebben Joop van der Horst en Marijke van der Wal de verandering van tweeledige naar eenledige negatie in het Nederlands beschreven. Zij betogen dat er een constructionele conditie is (V1-zinnen zijn progressief, bijzinnen zijn conservatief) en geven Noord-Zuid-verschillen aan. In vervolgstudies zijn de constructionele en regionale condities bevestigd, maar daarnaast zijn andere condities gesuggereerd, i.h.b. de fonetische context en de semantiek en frequentie van het hoofdwerkwoord. Bovendien is er aanleiding om een relatie tussen complexiteit en negatie te veronderstellen, in de zin dat complexe werkwoordclusters progressief zouden kunnen zijn. Ten slotte doet internationaal onderzoek vermoeden dat er een sociale conditie in het spel is. De zeventiende-en achttiende-eeuwse privébrieven uit het Brieven als Buit-corpus vormen een uitgelezen kans om kwantitatieve resultaten te verkrijgen over de verschillende condities en om het belang van specifieke condities vast te stellen.

\section{Negatie in de geschiedenis van het Nederlands}

De DBNL tophonderd voor de Nederlandse taalkunde bevat het inmiddels klassieke artikel Negatieverschijnselen en woordvolgorde in de geschiedenis van het Nederlands van de hand van Joop (J.M.) van der Horst en Marijke (M.J.) van der Wal, dat in 1979 in het Tijdschrift voor Nederlandse Taal-en Letterkunde (TNTL) verscheen. Het was een van de eerste artikelen van twee toen jonge onderzoekers die geïntrigeerd waren door veranderingen in het Nederlandse negatiesysteem. In een tijd van handmatig oudere teksten doorploegen, zinnen en verschijnselen noteren op systeemkaartjes, legden zij hun bevindingen naast elkaar, brachten zij de negatiefeiten voor verschillende eeuwen in kaart en zochten zij naar verklaringen. Het algemene beeld is bekend: de verandering van een eenledige preverbale negatie en $(n e, n)$ in het Oudnederlands naar een tweeledige negatie en...niet in het Middelnederlands en vervolgens naar de eenledige postverbale negatie niet in het huidige Nederlands. 
In het Middelnederlands komen overigens alle drie de opties naast elkaar voor: de preverbale negatie en met syntactische beperkingen, de tweeledige negatie als regel en de postverbale negatie niet als nieuwe ontwikkeling. In het TNTL-artikel lag de nadruk op de fase waarin de tweeledige negatie en...niet veranderde in de enkele negatie niet. Van der Horst en Van der Wal trachtten zicht te krijgen op de precieze gang van die verandering en onderzochten daarvoor "een representatieve groep teksten vanaf het vroege mnl. tot diep in de $17^{\text {de }}$ eeuw" (Van der Horst \& Van der Wal 1979:7). De verandering van tweeledige naar eenledige negatie trad ook bij andere negatieve woorden op zoals nie, niemant, niewer, geen, maar die bleven buiten beschouwing.

Hun onderzoek leverde verschillen tussen zinstypen op: V1-zinnen bleken bijvoorbeeld in de hele periode progressief te zijn met een hoog percentage enkel niet, terwijl bijzinnen in de zestiende en zeventiende eeuw conservatief waren met nog een hoog percentage tweeledige negatie. Tegelijkertijd kwamen voor de zestiende en zeventiende eeuw regionale verschillen aan het licht: het enkele niet bleek in die periode frequenter voor te komen in teksten uit het noorden dan uit het zuiden van het taalgebied (Van der Horst \& Van der Wal 1979:18-20). In deze bijdrage voor de scheidende Joop van der Horst stellen wij de vraag wat er na 35 jaar overeind staat van het eerste uitvoerige artikel over negatie in de geschiedenis van het Nederlands. ${ }^{1}$

Er zijn veel studies over negatieveranderingen gevolgd die deels voortgaan op constructionele condities en regionale variatie en deels andere condities suggereren zoals de fonetische context en de semantiek en de frequentie van het hoofdwerkwoord. De toegenomen aandacht onder taalkundigen voor het thema complexiteit geeft bovendien aanleiding om te veronderstellen dat er een relatie is tussen complexiteit en negatie, in de zin dat complexe werkwoordclusters mogelijk progressief zijn. Ten slotte suggereert internationaal onderzoek (o.a. naar het Engels) dat er een sociale conditie in het spel is. De betreffende literatuurverwijzingen zijn in de paragrafen 3 tot en met 7 te vinden.

Die vele aangevoerde factoren doen de vraag rijzen naar het belang van de verschillende genoemde condities. De zeventiende- en achttiende-eeuwse privébrieven uit het Brieven als Buit-corpus, recent algemeen toegankelijk op http://brievenalsbuit.inl.nl, bieden een uitgelezen mogelijkheid om kwantitatieve resultaten te verkrijgen over die verschillende condities en zo conclusies te trekken over de rol van verschillende factoren in dit specifieke taalveranderingsproces. 


\section{Het Brieven als Buit-corpus}

Voor nadere informatie over de achtergrond van de in oorlogstijden door Engelsen buitgemaakte brieven verwijzen we kortheidshalve naar www.brievenalsbuit.nl en naar Van der Wal, Rutten \& Simons (2012). Hier is van belang dat de regionale en sociale diversiteit van dit brievenmateriaal ons onderzoek naar de verschillende genoemde factoren mogelijk maakt. We gebruiken daarvoor met één uitzondering steeds het hele zeventiende-eeuwse Brieven als Buit-corpus d.w.z. 549 privébrieven (228.000 woorden) uit de periode 1665-1674, geschreven door 424 verschillende scribenten. Het zijn zowel vastgestelde autografen, als niet-autografen en brieven waarvan de autografische status onzeker is (zie voor de autografenproblematiek Nobels \& Van der Wal 2012). Voor ons onderzoek naar de sociale conditie komen alleen de 260 autografen in aanmerking, d.w.z. de facto de 210 autografen die gerelateerd konden worden aan een sociale klasse. Omdat uit eerder onderzoek (Rutten et al. 2012) is gebleken dat in ons laat-achttiende-eeuwse brievenmateriaal nauwelijks nog tweeledige negaties voorkomen, maken wij hier geen gebruik van dat deel van het Brieven als Buit-corpus.

In ons corpus bleken in totaal 2307 negatie-elementen voor te komen: 1501 enkele negatie (65\%) tegenover 806 tweeledige negatie (35\%). De meest frequente negator (al of niet tweeledig) was niet met 1830 voorkomens (79\%). De overige $21 \%$ omvat geen, niemand, nimmer, nooit.

\section{De constructionele en de regionale conditie}

De verspreiding van de nieuwe, enkele negatievariant per zinstype, de constructionele condities die Van der Horst \& Van der Wal identificeerden, zijn ook in volgend onderzoek bevestigd en dat geldt eveneens voor de regionale conditie, de verspreiding van de enkele negatie vanuit het noorden naar het zuiden (zie onder meer Burridge 1993, Rutten et al. 2012, Vosters \& Vandenbussche 2012). Van de 2307 negatievoorkomens werden er 1973 in V1-zinnen zoals (1), V2-hoofdzinnen (2) of Vfn-bijzinnen (3) aangetroffen.

\section{(1) ende en verkert altijt in geen herbergen \\ (2) ick en verget $v$ niet in mijn gebedt}




\section{(3) tabago dat sij nu noijt meer sien sal}

De verhoudingen tussen enkele en tweeledige negaties in deze zinstypen zijn in Tabel 1 weergegeven.

\begin{tabular}{|lrrrrr|}
\hline & \multicolumn{2}{c}{ Enkel } & \multicolumn{2}{c|}{ Tweeledig } & Totaal \\
\hline & $\mathrm{N}$ & $\%$ & $\mathrm{~N}$ & $\%$ & $\mathrm{~N}$ \\
V1 & 118 & 89 & 15 & 11 & 133 \\
V2-hoofdzin & 658 & 64 & 371 & 36 & 1029 \\
Vfn-bijzin & 458 & 56 & 353 & 44 & 811 \\
\hline Totaal & $\mathbf{1 2 3 4}$ & $\mathbf{6 3}$ & $\mathbf{7 3 9}$ & $\mathbf{3 7}$ & $\mathbf{1 9 7 3}$ \\
\hline
\end{tabular}

Tabel 1: Enkele en tweeledige negatie per zinstype

Uit Tabel 1 blijkt een evident verschil per zinstype: de V1-context is met $89 \%$ enkele negatie heel progressief, de V2 hoofdzinnen bevatten $64 \%$ enkele negatie en de Vfn-bijzinnen zijn met 56\% enkele negatie het conservatiefst. Deze verschillen gelden niet alleen voor het corpus als totaal, maar eveneens voor de negatievoorkomens per regio (zie Rutten et al. 2012: 334). De nieuwe variant verspreidt zich dus van het ene constructietype naar het andere (constructionele diffusie). Daarmee wordt de constructionele conditie in ons materiaal bevestigd en bovendien blijken dezelfde zinstypen als bij Van der Horst \& Van der Wal het meest progressief respectievelijk het meest conservatief.

Ook de frappante regionale verschillen die Van der Horst \& Van der Wal vaststelden voor de zestiende en zeventiende eeuw, werden bevestigd, onder meer in De Meersman (1981) voor het Vlaams en in Burridge (1993) voor het Brabants. Burridge (1993) liet zien dat het beslissende omslagpunt voor haar materiaal rond 1650 in Holland lag, waar de enkele negatie in teksten dominant was geworden, terwijl in zuidelijker regio's de tweeledige negatie nog in gebruik bleef. De vraag is nu wat ons latere brievenmateriaal (1665-1674) laat zien. De spreiding van de nieuwe, enkele negatie en de oudere, tweeledige negatie over de verschillende regio's blijkt uit Tabel 2 .

Uit Tabel 2 wordt niet alleen de eerder vastgestelde regionale diversiteit duidelijk, maar de Noord-Zuid tegenstelling wordt ook gepreciseerd. Van Noord-Holland (in ons brievenmateriaal vooral het gebied boven Amsterdam) naar Vlaanderen toe neemt het percentage enkele negatie af: van $88 \%$ in Noord-Holland, via 67\% in Amsterdam, naar $49 \%$ en $52 \%$ in Zuid-Holland en Zeeland, en vervolgens naar 
42\% in Vlaanderen waar de tweeledige negatie nog dominant is. De categorie Onbekend (negaties die niet aan een specifieke regio gekoppeld konden worden) vertoont met 62\% enkele negatie het algemene beeld van ongeveer tweederde enkele negatie. De opvallend hoge categorie Anders (91\% enkele negatie) bevat vooral voorkomens van scribenten afkomstig uit Friesland en Duits- en Noors-sprekende gebieden. In het Fries, Hoogduits, Nederduits en Noors heeft de verandering van tweeledige naar enkele negatie eerder plaatsgevonden dan in het Nederlands (zie Elspaß \& Langer 2012, Nevalainen \& Rutten 2012). De hoge frequentie van de enkele negatie zou in deze categorie verklaard kunnen worden als een geval van morfosyntactische impositie vanuit $\mathrm{L} 1$. Het is voorts opmerkelijk dat de brieven gerelateerd aan Amsterdam en Zuid-Holland nog zo veel tweeledige negaties bevatten, respectievelijk 33\% en 51\%, terwijl Burridge rond 1650 in Holland bijna uitsluitend enkele negatie aantrof. Hier blijkt dus het aanzienlijke verschil in corpusmateriaal: het verschil tussen Burridge's gedrukte, gepubliceerde teksten van rond 1650 en onze privébrieven van enkele decennia later.

\begin{tabular}{|lrlrrc|}
\hline & \multicolumn{2}{c}{ Enkel } & \multicolumn{2}{c}{ Tweeledig } & Totaal \\
\hline & $\mathrm{N}$ & $\%$ & $\mathrm{~N}$ & $\%$ & $\mathrm{~N}$ \\
Noord-Holland & 385 & 88 & 53 & 12 & 438 \\
Amsterdam & 523 & 67 & 253 & 33 & 776 \\
Zuid-Holland & 134 & 49 & 142 & 51 & 276 \\
Zeeland & 285 & 52 & 262 & 48 & 547 \\
Vlaanderen & 15 & 42 & 21 & 58 & 36 \\
Anders & 41 & 91 & 4 & 9 & 45 \\
Onbekend & 118 & 62 & 71 & 38 & 189 \\
\hline Totaal & $\mathbf{1 5 0 1}$ & $\mathbf{6 5}$ & $\mathbf{8 0 6}$ & $\mathbf{3 5}$ & $\mathbf{2 3 0 7}$ \\
\hline
\end{tabular}

Tabel 2: Enkele en tweeledige negatie per regio

$\mathrm{Nu}$ de constructionele en regionale conditie in ons brievenmateriaal zijn bevestigd richten we ons op de later gesuggereerde condities. Allereerst de fonetische context (par. 4), vervolgens de semantiek en de frequentie van het hoofdwerkwoord (par. 5) en tenslotte complexiteit (par. 6). Na de behandeling van deze interne factoren gaan we in par. 7 nader in op de sociale factor. 


\section{De fonetische context}

In verscheidene studies is het clitisch karakter van en benadrukt en is verondersteld dat de fonetische context (ook) een rol zou hebben gespeeld bij de wegval van en (De Haan \& Weerman 1984:183-186; Burridge 1993; Goss 2002). Burridge (1993) en Vosters (2011) laten zien dat de linker context $<\mathrm{n}>$ de wegval van het negatie-element en zou bevorderen, maar Hoeksema (1997) vond dit effect alleen bij het lexeem men. Om deze claims te onderzoeken onderscheiden we, in ansluiting bij Burridge (1993) en Vosters (2011), vijf verschillende fonetische linkercontexten: vocalen als in wij in (4), consonanten (m.u.v. $\langle\mathrm{n}\rangle$ ) als in tijt in (5), $<\mathrm{n}>($ m.u.v. $<\mathrm{en}>$ ) als in man in (6), <en $>$ (m.u.v. het lexeem men) als in (7), en het lexeem men (8).

(4) want wij en zijn het nijet weerdijgh vanwegen onse menijgh vuldijghe sonden

(5) want Jck geen tijt en hadden

(6) die man en wilde het gelt niet geeve

(7) capmessen met houte beften en zijn niet goet

(8) men en weet nijet ofte wij het lant sullen mogen houden

De spreiding van de negatie over deze verschillende contexten is te zien in Tabel 3. ${ }^{2}$

\begin{tabular}{|lrrrrr|}
\hline & \multicolumn{2}{c}{ Enkel } & \multicolumn{2}{c|}{ Tweeledig } & Totaal \\
\hline & $\mathrm{N}$ & $\%$ & $\mathrm{~N}$ & $\%$ & $\mathrm{~N}$ \\
$\mathrm{~V}$ & 242 & 61 & 155 & 39 & 397 \\
$\mathrm{C}$ & 807 & 60 & 528 & 40 & 1335 \\
$\langle\mathrm{n}\rangle$ & 55 & 62 & 34 & 38 & 89 \\
$\langle\mathrm{en}\rangle$ & 166 & 66 & 84 & 34 & 250 \\
men & 23 & 96 & 1 & 4 & 24 \\
\hline Totaal & $\mathbf{1 2 9 3}$ & $\mathbf{6 2}$ & $\mathbf{8 0 2}$ & $\mathbf{3 8}$ & $\mathbf{2 0 9 5}$ \\
\hline
\end{tabular}

Tabel 3: Enkele en tweeledige negatie per linkercontext 
De tabel laat zien dat er nauwelijks verschillen zijn tussen vocalen, consonanten, $\langle\mathrm{n}\rangle$ of $\langle$ en $>$ : het percentage van $60-66 \%$ correspondeert volledig met het algemene patroon van $65 \%$ enkele negatie. Dit houdt in dat de fonetische linkercontext geen beslissende invloed heeft op het type negatie. Alleen het lexeem men blijkt een heel progressieve context te zijn voor enkele negatie. Op lexeemniveau is er dus een vermijding van haplologie.

\section{Semantiek en frequentie van het werkwoord}

Het is in de literatuur meermaals geopperd dat bepaalde werkwoorden conservatief zijn, zowel bij de overgang van enkele naar tweeledige negatie in het vroege Middelnederlands, als bij de overgang van tweeledige naar enkele negatie in het Vroegnieuwnederlands (o.a. Burridge 1993; Hoeksema 1994, 1997; Vosters 2011). Drie verschillende hypothesen zijn uit de literatuur te distilleren: dat hoogfrequente werkwoorden conservatief zijn, dat hulpwerkwoorden en vooral modale werkwoorden conservatief zijn en dat negatief-polaire werkwoorden, waaronder 'psychologische' werkwoorden conservatief zijn.

Om te achterhalen wat de invloed is van de keuze van het werkwoord hebben we bij werkwoorden in het corpus de spreiding van enkele en tweeledige negatie onderzocht. We beperken ons hier tot de meest relevante resultaten. Tweeledige negatie komt gemiddeld in 35\% van de gevallen voor. Er blijkt een behoorlijke spreiding te zijn over de verschillende werkwoorden. Bij veel werkwoorden is het aandeel tweeledige negatie 30 à $40 \%$, maar sommige zijn progressief met minder dan 20\% tweeledige negatie, andere conservatief met meer dan $60 \%$ tweeledige negatie. De spreiding blijkt niet samen te hangen met frequentie. Veel voorkomende werkwoorden scoren ongeveer een derde tweeledige negatie: zijn (33\%), hebben (29\%), kunnen (34\%) en zullen (32\%). Uit de opsomming blijkt meteen dat hulpwerkwoorden van tijd of modaliteit niet opvallend conservatief zijn. Ook de negatiefpolaire werkwoorden hoeven (31\%), durven (31\%) en twijfelen (40\%) vallen niet op door conservatisme. Psychologische werkwoorden en mental-state verbs zijn zowel progressief (hopen 14\% tweeledig, vergeten $22 \%$ ) als conservatief (weten $45 \%$ tweeledig, denken $50 \%$, geloven $57 \%$ ). Kortom, onze resultaten bevestigen geen van de hypothesen.

Toch vinden we sterke verschillen tussen de werkwoorden. Hoe kunnen we die verklaren? We hebben gekeken naar de zinstypen waarin 
de meest progressieve $(<25 \%$ tweeledig) en de meest conservatieve (> 45\% tweeledig) werkwoorden voorkomen (Tabel 4 ). Het gaat om de progressieve werkwoorden hopen, maken, laten, gaan, vergeten en mogen, en de conservatieve werkwoorden doen, krijgen, geloven, verlaten, komen, believen, denken, gelieven en staan.

\begin{tabular}{|lrrrrrr|}
\hline & \multicolumn{2}{c}{ V1 } & \multicolumn{2}{c}{$\begin{array}{c}\text { V2- } \\
\text { hoofdzin }\end{array}$} & Vfn bijzin \\
\hline & N & $\%$ & N & $\%$ & N & $\%$ \\
Progressieve werkwoorden & 43 & 39 & 27 & 25 & 39 & 36 \\
Conservatieve werkwoorden & 11 & 8 & 44 & 31 & 86 & 61 \\
\hline
\end{tabular}

Tabel 4. Progressieve en conservatieve werkwoorden per zinstype

Progressieve werkwoorden blijken vaak met V1 voor te komen, met name werkwoorden als vergeten en laten in adhortatieve constructies. Conservatieve werkwoorden komen veel voor in bijzinnen, bijvoorbeeld krijgen in een klacht als dat ick geen briefen uan u en krigh. Het is op zichzelf interessant dat werkwoorden vaak in bepaalde constructies voorkomen, maar hier concluderen we dat primair de zinstypen doorslaggevend lijken voor de keuze van het negatietype.

\section{Complexiteit}

Complexiteit is een onderwerp dat erg in de taalkundige belangstelling staat (bijv. Sampson, Gil \& Trudgill 2009). Met name twee typen complexiteit zouden een bevorderende werking gehad kunnen hebben op de overgang van tweeledige naar enkele negatie. De twee elementen van een tweeledige negatie staan vaak niet bij elkaar. De afstand tussen beide elementen kan als een complexiteitsmaat worden opgevat, waarbij de verwachting zou zijn dat de kans dat het onbeklemtoonde, historische negatiepartikel vervalt, toeneemt naarmate de afstand groter wordt. We zullen elders laten zien dat een grotere afstand inderdaad correleert met meer enkele negaties.

Hier concentreren we ons op een tweede type complexiteit, namelijk die van het werkwoordcluster. In bijzinnen staan ook in de latere zeventiende eeuw de werkwoorden vaak gegroepeerd aan het eind. De negatie gaat daar onmiddellijk aan vooraf, waarbij het historische partikel, dat doorgaans onmiddellijk aan de persoonsvorm voorafgaat, prototypisch tussen de beklemtoonde negator (bijv. niet) en de 
werkwoordelijke eindgroep ingeklemd staat (niet en sal sijn) of midden in de verbale cluster (niet seggen en can). Onze hypothese is dat een grotere werkwoordelijk eindgroep deletie van het partikel bevordert. We beperken ons dus tot bijzinnen, meer bepaald tot bijzinnen met niet. Van de 597 bijzinnen met niet hebben er 264 een enkel werkwoord, 300 een tweeledige eindgroep, 31 een drieledige eindgroep en 3 een vierledige eindgroep. De spreiding over de negatietypen staat in Tabel 5 .

\begin{tabular}{|lrrrr|}
\hline & \multicolumn{2}{c}{ Enkel } & \multicolumn{2}{c|}{ Tweeledig } \\
\hline & $\mathrm{N}$ & $\%$ & $\mathrm{~N}$ & $\%$ \\
Ww-groep 1 & 111 & 42 & 153 & 58 \\
Ww-groep 2 & 189 & 63 & 111 & 37 \\
Ww-groep 3 & 22 & 71 & 9 & 29 \\
Ww-groep 4 & 3 & 100 & 0 & 0 \\
\hline
\end{tabular}

Tabel 5. Enkele en tweeledige negatie per werkwoordelijke eindgroep

In bijzinnen in het algemeen komt enkele negatie in 56\% van de gevallen voor (Tabel 1). Bij twee- en meerledige werkwoordelijke groepen is de enkele negatie nog dominanter. Maar vooral opvallend is het zeer conservatieve resultaat voor bijzinnen met maar één werkwoordsvorm: daar domineert de tweeledige negatie met $58 \%$. Het lijkt er dus sterk op dat complexere verbale clusters deletie van het negatiepartikel bevorderen.

\section{Sociale variabelen}

Taalgebruikers waren zich tegen het midden van de zeventiende eeuw bewust van de negatieverandering. Auteurs als Hooft (1581-1647) en Vondel (1587-1679) gingen vanaf ongeveer 1640 van zowel tweeledige als enkele negatie in eerdere teksten over op vrijwel uitsluitend enkele negatie (Van der Wal 1990: 64, Van der Wouden 1998). Tijdgenoten zoals de Zeeuwen Cats (1577-1660) en De Brune (1588-1658) bleven echter beide varianten gebruiken (Van der Wal 1990: 63-64). Rond dezelfde tijd verwierp de grammaticus Petrus Leupenius (1653) ook de tweeledige negatie als iets onlogisch (Van der Horst \&Van der Wal 1979:17). Latere taalbeschouwers in de Nederlandse en in anderstalige tradities zijn dezelfde mening toegedaan (Nevalainen \& Rutten 2012). Deze literaire en taalbeschouwelijke bronnen duiden erop dat de negatieverandering een 
verandering "above the level of awareness" moet zijn geweest en dat maakt het voorkomen van sociale variatie aannemelijk. Om dat aan te tonen onderzoeken we de zeventiende-eeuwse autografen in ons corpus (zie par. 2) en gaan we na of sociale klasse, gender of leeftijd bepalende factoren bij de negatieverandering zijn.

Bij ons onderzoek onderscheiden we, in navolging van historici (zie Frijhoff \& Spies 1999:180-190), vier sociale klassen die zich bevinden onder de hoogste klasse van regenten en patriciaat: de lage klasse (L), de lage-middenklasse (LM), de hoge-middenklasse (HM) en hoge klasse (H) (zie voor een nadere toelichting Nobels 2013:35-39 en Simons 2013:96-101). Tabel 6 geeft aan hoe de spreiding van enkele en tweeledige negatie over de sociale klassen uitvalt.

\begin{tabular}{|lrrrrr|}
\hline & \multicolumn{2}{c}{ Enkel } & \multicolumn{2}{c}{ Tweeledig } & Totaal \\
\hline & $\mathrm{N}$ & $\%$ & $\mathrm{~N}$ & $\%$ & $\mathrm{~N}$ \\
L & 33 & 59 & 23 & 41 & 56 \\
LM & 155 & 60 & 102 & 40 & 257 \\
HM & 427 & 67 & 212 & 33 & 639 \\
H & 93 & 70 & 40 & 30 & 133 \\
\hline Totaal & $\mathbf{7 0 8}$ & $\mathbf{6 5}$ & $\mathbf{3 7 7}$ & $\mathbf{3 5}$ & $\mathbf{1 0 8 5}$ \\
\hline
\end{tabular}

Tabel 6. Enkele en tweeledige negatie per sociale klasse

De twee lagere klassen gebruiken ongeveer $60 \%$ enkele negatie, terwijl het percentage stijgt naar $70 \%$ in de hoge klasse. De onderlinge verschillen zijn klein, en dat blijkt ook het geval te zijn bij de gendervariabele zoals in Tabel 7 is te zien.

\begin{tabular}{|lrrrrr|}
\hline & \multicolumn{2}{c}{ Enkel } & \multicolumn{2}{c}{ Tweeledig } & Totaal \\
\hline & $\mathrm{N}$ & $\%$ & $\mathrm{~N}$ & $\%$ & $\mathrm{~N}$ \\
Man & 507 & 66 & 263 & 34 & 770 \\
Vrouw & 284 & 58 & 207 & 42 & 491 \\
\hline Totaal & $\mathbf{7 9 1}$ & $\mathbf{6 3}$ & $\mathbf{4 7 0}$ & $\mathbf{3 7}$ & $\mathbf{1 2 6 1}$ \\
\hline
\end{tabular}

Tabel 7. Enkele en tweeledige negatie per gender 
De kleine klasseverschillen en de eveneens kleine genderverschillen zijn wel in lijn met de verwachtingen voor een gemarkeerd taalverschijnsel. In de hogere klassen en bij de mannen, die over het algemeen meer opleiding hebben genoten en meer schrijfervaring hebben dan de lagere klassen en vrouwen, wordt de nieuwere variant meer gehanteerd. Bovendien vertoonden gedrukte teksten al in 1650 vrijwel uitsluitend enkele negatie (par. 3) - en gedrukte teksten waren in meerderheid afkomstig van mannelijke schrijvers uit de hogere (midden-)klasse.

Wat de variabele leeftijd betreft zien wij geen opmerkelijke verschillen tussen de drie onderscheiden leeftijdsgroepen: de groep jonger dan 30, de leeftijd 30 tot 50 en de scribenten ouder dan 50 (zie Tabel 8). De verschillen zijn klein en het percentage komt overeen met het globale aandeel van ongeveer tweederde enkele negatie.

\begin{tabular}{|lrrrrr|}
\hline & \multicolumn{2}{c}{ Enkel } & \multicolumn{2}{c}{ Tweeledig } & Totaal \\
\hline & $\mathrm{N}$ & $\%$ & $\mathrm{~N}$ & $\%$ & $\mathrm{~N}$ \\
$<30$ & 314 & 60 & 212 & 40 & 526 \\
$30-50$ & 375 & 65 & 200 & 35 & 575 \\
$>50$ & 63 & 62 & 39 & 38 & 102 \\
\hline Totaal & $\mathbf{7 5 2}$ & $\mathbf{6 3}$ & $\mathbf{4 5 1}$ & $\mathbf{3 7}$ & $\mathbf{1 2 0 3}$ \\
\hline
\end{tabular}

Tabel 8. Enkele en tweeledige negatie per leeftijdsgroep

Die kleine verschillen zijn ook een indicatie dat taalgebruikers zich bewust waren van de negatieverandering. Bij een verandering "below the level of social awareness" zouden we wel verschillen verwachten, namelijk een geleidelijke toename van de enkele negatie van de oude naar de jongere leeftijdsgroepen.

De vraag zou nog gesteld kunnen worden hoe deze beperkte klasseen gendervariatie interfereert met de eerder vastgestelde robuuste regionale en constructionele condities. Binnen het bestek van dit in omvang beperkte artikel kunnen we daar niet verder op ingaan. We vermelden slechts dat ons onderzoek naar de twee regio's met het grootste aantal gegevens, Amsterdam en Zeeland, twee hoofdbevindingen heeft opgeleverd die geheel overeenstemmen met onze conclusies hier: namelijk dat de enkele negatie frequenter was in de twee hoogste dan in de twee laagste klassen en eveneens frequenter bij mannen dan bij vrouwen. 


\section{Conclusies}

Negatie is waarschijnlijk een van de meest onderzochte taalverschijnselen. Voor het Nederlands stond Joop van der Horst mee aan de basis van een redelijk uitvoerige literatuur, waarin allerlei factoren zijn genoemd die de keuze tussen enkele en tweeledige negatie zouden beïnvloeden. In dit artikel hebben we in vogelvlucht enkele van die factoren getest op het Brieven als Buit-corpus. Enige invloed van de fonetische (eigenlijk: orthografische) linkercontext konden we niet vinden. Het type werkwoord (in termen van de semantiek of de frequentie ervan) leek evenmin van invloed op de negatie. Wel konden we het belang aantonen van enkele nieuwe factoren, namelijk complexiteit en, in minder mate, sociale variabelen. Maar boven alles uit torent de observatie die al in 1979 is gedaan en die we alleen hebben kunnen preciseren: zinstype en regio zijn doorslaggevend.

\section{Noten}

1. Zie ook Van der Horst \& Van der Wal (1984) voor een nadere argumentatie van de in het artikel van 1979 gekozen benadering.

2. Het totale aantal van 2095 voorkomens is lager dan de eerdere 2307 , omdat ambiguë gevallen en V1-zinnen waar de linkercontext het zinseinde is, afvielen.

\section{Geraadpleegde literatuur}

Brieven als Buit-corpus: http://brievenalsbuit.inl.nl

Burridge, Kate. 1993. Syntactic change in Germanic: Aspects of language change in Germanic with particular reference to Middle Dutch. Amsterdam \& Philadelphia: Benjamins.

Elspaß, Stephan \& Nils Langer. 2012. Jespersen's cycle and the history of German negation: Challenges from a sociolinguistic perspective. Neuphilologische Mitteilungen 113.275-292.

Frijhoff, Willem \& Marijke Spies. 1999. 1650. Bevochten eendracht. Den Haag: Sdu.

Goss, Emily L. 2002. Negotiated language change in Early Modern Holland: Immigration and linguistic variation in The Hague (1600-1670). Unpublished dissertation. Madison: University of Wisconsin.

de Haan, Ger J. \& Fred Weerman. 1984. Taaltypologie, taalverandering en mogelijke grammatica's: het Middelnederlandse "en". Tijdschrift voor Nederlandse Taal-en Letterkunde 100. 161-190.

Hoeksema, Jack. 1994. On the grammaticalization of negative polarity items. Proceedings of the Annual Meeting of the Berkeley Linguistics Society 20.273-282.

Hoeksema, Jacob. 1997. Negation and negative concord in Middle Dutch. In Danielle Forget, Paul Hirschbühler, France Martineau \& María-Luisa Rive- 
ro (eds), Negation and polarity: Syntax and semantics, 139-156. Amsterdam \& Philadelphia: John Benjamins.

van der Horst, Joop \& Marijke van der Wal. 1979. Negatieverschijnselen en woordvolgorde in de geschiedenis van het Nederlands. Tijdschrift voor Nederlandse Taalen Letterkunde 95. 6-37.

van der Horst, Joop \& Marijke van der Wal. 1984. Een repliek. Tijdschrift voor Nederlandse Taal-en Letterkunde 100. 283-293.

de Meersman, Alfons. 1981. Ontkenningen in ouder Nederlands. Studia Germanica Gandensia 21, 5-14.

Nevalainen, Terttu \& Gijsbert Rutten. 2012. Introduction: comparative historical sociolinguistics and the history of negation. Neuphilologische Mitteilungen 113. 261-273.

Nobels, Judith. 2013. (Extra) Ordinary letters: A view from below on seventeenth-century Dutch. Utrecht: LOT.

Nobels, Judith \& Marijke van der Wal. 2012. Linking words to writers: Building a reliable corpus for historical sociolinguistic research. In Nils Langer, Steffan Davies \& Wim Vandenbussche (eds.), Language and history, linguistics and historiography: Interdisciplinary approaches, 343-361. Bern etc.: Peter Lang.

Rutten, Gijsbert, Marijke van der Wal, Judith Nobels \& Tanja Simons. 2012. Negation in seventeenth- and eighteenth-century Dutch: A historical-sociolinguistic perspective. Neuphilologische Mitteilungen 113.323-342.

Sampson, Geoffrey, David Gil \& Peter Trudgill. 2009. Language complexity as an evolving variable. Oxford: Oxford University Press.

Simons, Tanja. 2013. Ongekend $18^{e}$-eeuws Nederlands: Taalvariatie in persoonlijke brieven. Utrecht: LOT.

Vosters, Rik. 2011. Taalgebruik, taalnormen en taalbeschouwing in Vlaanderen tijdens het Verenigd Koninkrijk der Nederlanden: Een historisch-sociolingü̈stische verkenning van vroeg-negentiende-eeuws Zuidelijk Nederlands. Proefschrift. Brussel: Vrije Universiteit Brussel.

Vosters, Rik \& Wim Vandenbussche. 2012. Bipartite negation in 18th and early 19th century Southern Dutch: Sociolinguistic aspects of norms and variation. Neuphilologische Mitteilungen 113.343-364.

van der Wal, Marijke van der. 1990. Taalidealen, taalnormen en taalverandering: Johan de Brune in linguïstisch perspectief. In P.J. Verkruijsse (ed.), Johan de Brune de Oude (1588-1658): Een Zeeuws literator en staatsman uit de zeventiende eeuw, 54-68. Middelburg: Koninklijk Zeeuwsch Genootschap der Wetenschappen.

van der Wal, Marijke, Gijsbert Rutten \& Tanja Simons. 2012. Letters as loot. Confiscated letters filling major gaps in the history of Dutch. In Marina Dossena \& Gabriella Del Lungo Camiciotti (eds.), Letter writing in Late Modern Europe, 139-161. Amsterdam \& Philadelphia: John Benjamins.

van der Wouden, Ton. 1998. On the development of marked negation systems: The Dutch situation in the seventeenth century. In Richard M. Hogg \& Linda van Bergen (eds), Historical Linguistics 1995, Volume 2,311-329. Amsterdam \& Philadelphia: John Benjamins. 